\title{
Decreased Renal Perfusion after Correction of Experimental Coarctation
}

\author{
M. TARKKA, M. UHARI, J. HEIKKILÄ, AND A. PAKARINEN \\ Departments of Surgery [M.T.], Pediatrics [M.U.], and Clinical Chemistry [J.H., A.P.], University of Oulu, \\ Oulu, Finland
}

\begin{abstract}
Hemodynamical changes in coarctation were studied with an experimental model. Coarctation of the thoracic aorta was induced in seven puppies at the age of 8 wk. After a 7-month follow-up period a corrective operation with a venous patch was performed. Two dogs were lost a few hours after the correction operation. The remaining five dogs were followed for 12 months postoperatively. Renal perfusion was measured with a ${ }^{133}$ Xenon washout method just prior to the operation, $1 \mathrm{~h}, 6$ and 12 months postoperatively. The glomerular filtration rate was measured using the ${ }^{51} \mathrm{Cr}$-EDTA method 1 wk before the operation, $3 \mathrm{wk}, 2,6$, and 12 months after it. Six healthy adult dogs were used as controls for glomerular filtration rate measurements. Peripheral renin activity was measured at operation, just before the correction of aortic coarctation, $1 / 2,1 \mathrm{~h}, 1,3,7$ days, 2 and 6 months after the correction operation. Renal perfusion decreased significantly $(p<$ 0.05 ) immediately after the correction operation and rose again during the follow-up. Peripheral renin activity rose significantly $(p<0.01)$ from the preoperative values and was at its greatest 1 day after the operation. Later on, peripheral renin activity values returned to normal. Coarctated dogs had significantly $(p<0.01)$ lower glomerular filtration rate values than controls in each measurement except at the 2 months postoperative measurement. These results support decreased renal perfusion with resultant increased peripheral renin activity as part of the pathomechanism of the paradoxical hypertension observed after correction of coarctation. (Pediatr Res 22:445-448, 1987)
\end{abstract}

\section{Abbreviations}

CoA, aortic coarctation

RP, renal perfusion

PRA, plasma renin activity

GFR, glomerular filtration rate

BP, blood pressure

Operative correction of CoA was first performed approximately 40 yr ago (1). Despite the good overall postoperative results, there are complications and symptoms such as paradoxical hypertension and long-term hypertension occuring after the corrective operation of thoracic CoA (2-4). The pathomechanisms of paradoxical hypertension have been widely studied, but the postoperative hemodynamical changes are still unknown.

Attention has been paid to the possible role of the kidneys in

Received October 30, 1986; accepted May 18, 1987

Correspondence Matti Tarkka, M.D., Department of Surgery, University of Oulu, SF-90220 Oulu, Finland.

Supported by the Paavo Nurmi's Foundation to M. Tarkka during the study is acknowledged. both short- and long-term postoperative findings. Rocchini et al. (5) found that renin activity was significantly increased immediately postoperatively. Before the studies of the activity of reninangiotensin system it was suggested that a high set of the baroreceptors will increase the release of norepinephrine thus causing hypertension $(6,7)$. Also, there are certain structural changes found both in the aorta and coronary arteries which may contribute to the pathomechanism of long-term hypertension $(8,9)$.

Because the methods to accurately measure renal hemodynamics are invasive, we developed an experimental model to study hemodynamical changes in CoA (10). Herein we report the results on the studies of RP, PRA, and GFR performed preoperatively, at the operation, and postoperatively in dogs.

\section{MATERIALS AND METHODS}

Coarctation of the thoracic aorta was induced in seven puppies at the age of $8 \mathrm{wk}$ with a silk ligature just distal to the origin of the left subclavian artery (10). The weights of the puppies varied from 1840 to $2620 \mathrm{~g}$. After a 7-month follow-up period when the dogs were 9 months old, a correction operation was performed. At operation, the constriction of the thoracic aorta was corrected with a venous patch taken from the left external jugular vein. Two dogs were lost because of postoperative respiratory insufficiency due to anesthesia a few hours after the correction operation. There were no operative complications during the procedures. The remaining five dogs were followed for 12 months postoperatively. Thus the total follow-up time was $1 \mathrm{yr}$ and 7 months in each dog.

RP was measured with a ${ }^{133}$ Xenon washout method just before and $a 1 / 2 h$ after correction of COA (11). During the follow-up period RP was measured both 6 and 12 months postoperatively. The dogs were anesthetized with pentobarbitalsodium (30-40 $\mathrm{mg} / \mathrm{kg}$ ), intubated and breathed spontaneously during the measurements. A $40-200 \mathrm{MBq}(1-5 \mathrm{mCi})$ dose of ${ }^{133} \mathrm{Xe}$ in $1-2.5 \mathrm{ml}$ of saline was used. The injection was given through a catheter placed into the aorta above the origin of the renal arteries via the femoral artery. BP was measured from the aortal catheter before and after the RP measurement with a strain-gauge transducer and a multichannel recorder (Hewlett-Packard Co., Palo Alto, CA).

The glomerular filtration rate was determined using the ${ }^{51} \mathrm{Cr}$ EDTA method by taking blood samples 90,150 , and $210 \mathrm{~min}$ after an intravenous injection of ${ }^{51} \mathrm{Cr}$-EDTA. GFR was calculated on the basis of the decrease in radioactivity in the blood samples. GFR was measured 1 wk before the operation and $3 \mathrm{wk}, 2,6$, and 12 months after operation. Six healthy adult dogs living in the same laboratory environment and who were about the same age were used as controls for GFR measurements.

Plasma renin activity was determined using reagent kits from Clinical Assays, Inc., Cambridge, MA according to the manufacturer's instructions. The measurements were performed at operation, just before the correction of $\operatorname{CoA}$ and $1 / 2$ and $1 \mathrm{~h}$ after the 
operation. Later, PRA was measured 1, 3, and 7 days and 2 and 6 months after the correction operation.

Development of hypertension was followed by measuring BP regularly from the left front leg of the dogs with an ultrasound device (Arteriosonde, Roche). For this measurement, no anesthesia was necessary. Earlier we found that indirectly measured values correlated well with directly measured values (11).

Cardiac output was measured by thermodilution simultaneously with RP measurements immediately before and a $1 / 2 \mathrm{~h}$ after the correction operation.

Significance values of differences measured at the different occasions were analyzed first with a two-way analysis of variance and if this gave a significant $F$ value, analysis was continued with a paired $t$ test. Our "goal" was to test the differences of the values before and after the correction operation. The paired comparisons were thus made only with these values. The differences to the values of the control group were tested with an unpaired $t$ test.

\section{RESULTS}

The mean weight of the dogs after follow-up time was $11.9 \mathrm{~kg}$, weight varying from 10.9 to $13.2 \mathrm{~kg}$. Hypertension above the coarctation developed in each dog, the mean BP being 216/124 $\mathrm{mm} \mathrm{Hg}$, as measured indirectly. The dogs remained hypertensive even after the correction operation (Fig. 1).

One dog had a significant systolic gradient, i.e. $15 \mathrm{~mm} \mathrm{Hg}$, after the correction operation. Three dogs had no gradient and one dog had a $5 \mathrm{~mm} \mathrm{Hg}$ gradient in the thoracic aorta postoperatively in anesthesia. At operation, pulse pressure below the coarctation rose significantly from the mean value of $9 \mathrm{~mm} \mathrm{Hg}$ (SD 5) before the correction to the value of $22 \mathrm{~mm} \mathrm{Hg}$ (SD 6, $p$ $<0.01$ ) postoperatively. The mean BP values in the distal aorta remained at the same level; it was $82 \mathrm{~mm} \mathrm{Hg}$ (SD 16) before and $86 \mathrm{~mm} \mathrm{Hg}$ (SD 12) after the operation. Cardiac output remained about the same and was $2.4 \mathrm{l} / \mathrm{min}$ (SD 0.9) preoperatively and $2.2 \mathrm{l} / \mathrm{min}$ (SD 0.7 ) $1 \mathrm{~h}$ postoperatively.

RPs decreased significantly from preoperative values of 2.83 (SD 0.75$)$ to $2.39(\mathrm{SD} 0.45) \mathrm{ml} / \mathrm{min} / \mathrm{g}(p<0.05)$ immediately after the correction operation (Fig. 2.) and rose again during the follow-up (Fig. 3.). PRA rose significantly $(p<0.01)$ from the preoperative values of 2.8 (SD 1.69) $\mu \mathrm{g} / \mathrm{liter} / \mathrm{h}$ and was at a maximum 1 day after the operation and was 6.4 (SD 3.99) $\mu \mathrm{g} /$ liter/h (Fig. 4.). Later, PRA values returned to normal (Fig. 5.).

The GFR rose temporarily as compared to the preoperative values 2 months postoperatively (Fig. 6.). The mean GFR of the control group was $55.3 \mathrm{ml} / \mathrm{min}$ (SD 11.1). When comparing this to the respective value of coarctated dogs, they had significantly $(p<0.01)$ lower values in each measurement except at the 2 month postoperative measurement.

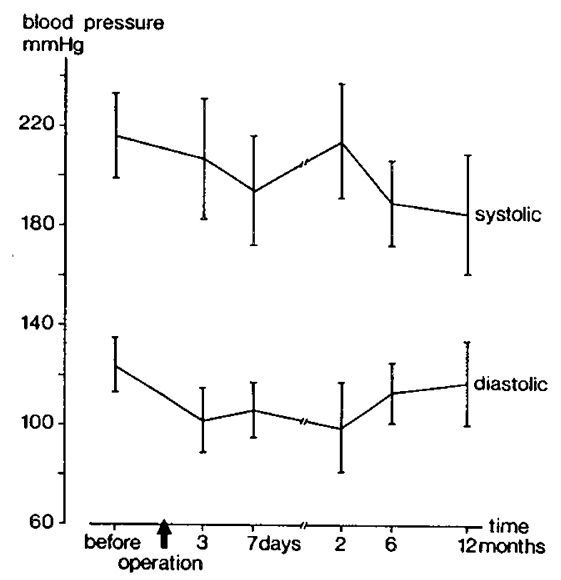

Fig. 1. Blood pressure (mean, SD) in the proximal aorta before correction of $\mathrm{CoA}$ and 3 days, 7 days, 2, 6, and 12 months postoperatively. Measured indirectly without anesthesia in five dogs.

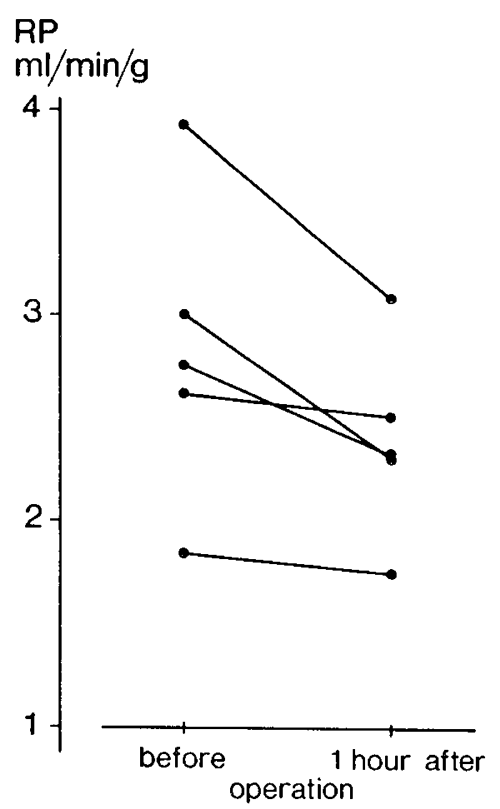

Fig. 2. RP values before and $1 \mathrm{~h}$ after correction of CoA in five dogs. The decrease from 2.83 to $2.39 \mathrm{ml} / \mathrm{min} / \mathrm{g}$ is statistically significant ( $p<$ $0.05)$.

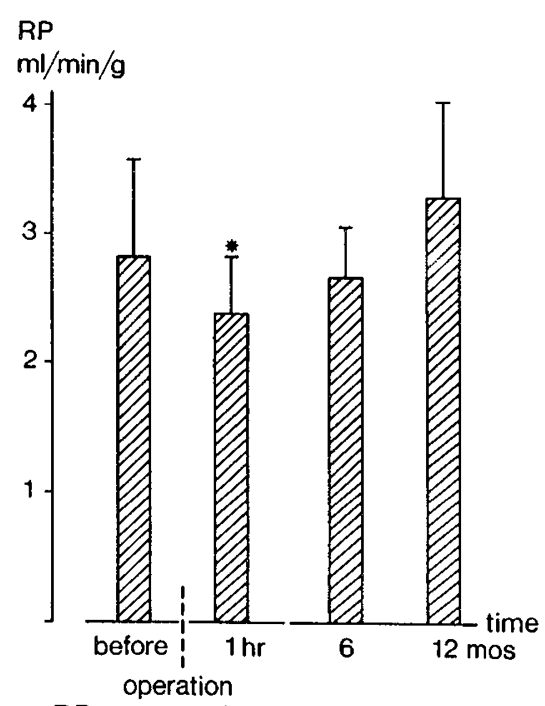

Fig. 3. Mean RP preoperatively and $1 \mathrm{~h}, 6$ and 12 months after correction of $\mathrm{CoA}$ in five dogs. The mean value $1 \mathrm{~h}$ after the operation is significantly decreased $(p<0.05)$.

\section{DISCUSSION}

Paradoxical hypertension after CoA operation occurs in $37-$ $100 \%$ of operated patients $(3,7)$. Gastrointestinal and neurological symptoms occur in $2-28 \%$ of patients $(3,12)$. The significant decrease in RP and the significant increase in PRA after the correction operation found in our study may well be the basic pathomechanism responsible for the rise in BP occurring 1 to 2 days after the operation in coarctated patients. We did not measure BP systematically during the first 2 days after the operation and so any possible paradoxical hypertension was not detected. On the $3 \mathrm{rd}$ postoperative day BP was not increased as compared to preoperative values. Also PRA activity was decreased to nearly preoperative values.

In the dogs with corrected $\operatorname{CoA} \mathrm{BP}$ remained higher than in the controls. In our earlier study we found significant morphological changes in the aortal wall (8). Failure of reversal of these structural changes may be the cause of the permanent hypertension in the coarctated dogs. 


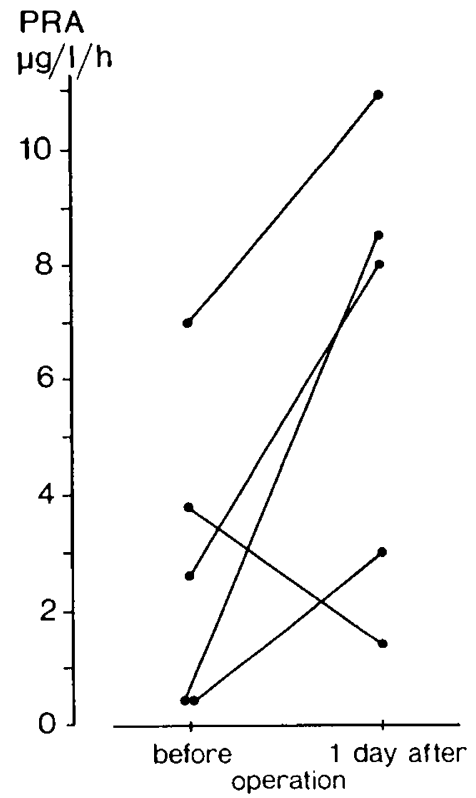

Fig. 4. PRA before and 1 day after correction of CoA in five dogs. The activity rose significantly (mean value from 2.8 to $6.4 \mu \mathrm{g} / \mathrm{liter} / \mathrm{h}, p$ $<0.01$ )

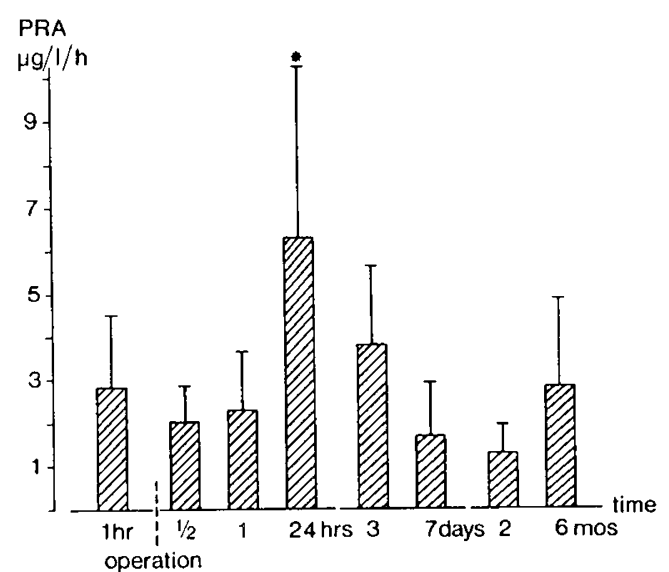

Fig. 5. Mean PRA before and after correction of CoA. The mean value $24 \mathrm{~h}$ postoperatively is significantly increased $(p<0.01)$.

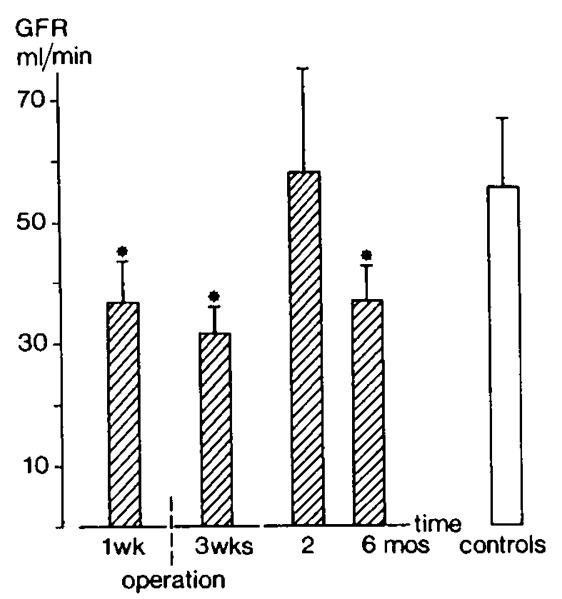

Fig. 6. Mean GFR values before and $3 \mathrm{wk}, 2$ and 6 months after correction of $\mathrm{CoA}$ in five dogs. Six healthy dogs were used as controls. *GFR is significantly lower $(p<0.01)$ as compared to controls.
Rocchini et al. (5) found increased PRA in patients operated on for coarctation. PRA is stimulated in different kinds of stress conditions and its increase may have been caused by the operation only. The finding of a postoperative decrease in RP strongly supports the pathophysiological importance of a high PRA in paradoxical hypertension. The postcoarcectomy syndrome with paradoxical hypertension, abdominal pain and tenderness, intestinal bleeding, fever, and leucocytosis has been suggested to be caused by severe, reactive vasospasm (12). Our finding of decreased RP after correction of CoA supports this mechanism.

Collateral circulation in coarctation is so well developed that there is no decrease in RP, even though the aorta is closed (10). Thus the magnitude of the circulation is normal, but there is a remarkably decreased pulsation in the circulation. The only marked postoperative hemodynamical change in the circulation below the coarctation was increased pulse pressure. Cardiac output and blood pressure remained at about the same level. It may be that the sudden pulsative blood flow causes a vasoconstriction in the vessels of the kidneys and leads to a decrease in RP. Another possibility to the vasospasm of renal vessels could be an increased activity of the renin-angiotensin system. We found, however, a decreased RP $1 \mathrm{~h}$ after correction of CoA and at that time PRA was still normal.

Moreno et al. (13) speculated that hypoperfusion distal to CoA during correction operation is the cause of the postcoarcectomy syndrome. The excellent collateral circulation that develops in severe $\mathrm{CoA}$ as in our experimental model, does not support this (10). It should be remembered, however, that the development of collateral circulation is dependent on the severity of the constriction. In mild $\mathrm{CoA}$ cases collateral circulation is poorly developed and thus the closure of the aorta may lead to ischemic damages. Yet the most serious form of these kinds of complications is the paralysis of the lower limbs postoperatively, with a frequency of about $0.4 \%$ (14).

Stimulation of the adrenal medulla to secrete more catecholamines is a common theory to explain the pathomechanisms of the postcoarcectomy syndrome. Benedict et al. (15) measured the concentrations of norepinephrine, epinephrine, and the activity of dopamine- $\beta$-hydroxylase in the urine of patients undergoing coarcectomy and compared these results to those of control patients who had other types of major operations. As expected, concentrations of these hormones rose in both groups, but much less in the control group (15). Earlier, Sealy (6) reported similar results, observing a good BP response to sympathetic blocking agents. In a situation of decreased blood flow and imminent ischemia it is logical to find increased secretion of epinephrine and norepinephrine.

We found previously that RP was not permanently decreased in our experimental CoA as compared to the control dogs (11). In the present study there was a significant decrease in GFR as compared to the controls. This difference disappeared temporarily 2 months after the CoA operation. Even though there was a change in GFR, no difference was found in other function studies of the kidneys. Bagby et al. (16) found that in normal conditions in their experimental CoA, kidney function studies were comparable to that of the controls. When the coarctated animals were stressed with dehydration or furosemide, there was a significant decrease in the function of the kidneys of the CoA animals as compared to the controls. It seems that our finding of decreased GFR has no clinical importance in normal situations, but it may mean that the reserve capacity of the kidneys in $\mathrm{COA}$ is significantly decreased.

Observations of a small number of patients undergoing $\mathrm{CoA}$ operation have shown that PRA increases and may cause paradoxical hypertension postoperatively (5). Parker et al. (17) found a decrease in BP during an angiotensin antagonist (Saralasin) test in six of eight patients after correction of aortic coarctation, indicating the role of the renin-angiotensin system in the pathomechanism of paradoxical hypertension. 
There are no studies available regarding the hemodynamic changes in patients after a correction operation. The present results in dogs implicate decreased RP which causes increased PRA and high blood pressure as part of the pathomechanism. It may be that the blood flow also is decreased in the mesenteric arteries. Our findings are clinically important and thus they indicate the urgent need of this kind of study in patients after coarcectomy.

\section{REFERENCES}

1. Crafoord C, Nyling G 1945 Congenital coarctation of aorta and its surgical treatment. J Thorac Surg 14:347-36I

2. Nanton MA, Olley PM 1976 Residual hypertension after coarctectomy in children. Am J Cardiol 37:769-772

3. Fox S, Pierce WS, Waldhausen JA 1980 Pathogenesis of paradoxal hypertension after coarctation repair. Ann Thorac Surg 29:135-141

4. Beerman LB, Neches WH, Patnode RE, Fricker FJ, Mathews RA, Park SC 1980 Coarctation of the aorta in children, late results after surgery. Am J Dis Child 134:464-466

5. Rocchini AP, Rosenthal A, Barger AC, Castaneda AR, Nadas A 1976 Pathogenesis of paradoxal hypertension after coarctation resection. Circulation 54:382-387

6. Sealy WC 1967 Coarctation of the aorta and hypertension. Ann Thorac Surg $3: 15-28$

7. Verska JJ, DeQuattro V, Woolley MM 1969 Coarctation of the aorta, the abdominal pain syndrome and paradoxal hypertension. J Thorac Cardiovasc
Surg 58:746-753

8. Uhari M, Tarkka M, Reinilä A, Heikkinen E 1982 Morphology of the great arteries in chronic experimental coarctation in dogs. Br J Exp Pathol 63:361377

9. Sehested J, Baadrup U, Mikkelsen E 1982 Different reactivity and structure of the prestenotic and poststenotic aorta in human coarctation. Circulation 65:1060-1065

10. Tarkka M, Uhari M, Koskinen M, Heikkinen E 1982 Experimental aortic coarctation in puppies. J Surg Res 33:208-213

11. Uhari M, Tarkka M, Koskinen M 1986 Renal perfusion in experimental coarctation of the aorta during antihypertensive therapy. Pediatr Cardiol 7:83-87

12. Ho ECK, Moss AJ 1972 The syndrome of "mesenteric arteritis" following surgical repair of aortic coarctation. Pediatrics 49:40-45

13. Moreno NN, deCampo T, Kaiser GA, Pallares VS 1980 Technical and pharmocologic management of distal hypotension during repair of coarctation of the aorta. J Thorac Cardiovasc Surg 80:182-186

14. Brewer LA, Fusburg RG, Mulder GA, Verska JJ 1972 Spinal cord complication following surgery for coarctation of the aorta. J Thorac Cardiovasc Surg 64:368-373

15. Benedict CR, Grahame-Smith DG, Fisher A 1978 Changes in plasma cathecholamines and dopamine beta-hydroxylase after correction surgery for coarctation of aorta. Circulation 57:598-602

16. Bagby SP, McDonald WJ, Strong DW, Porter GA, Bennet WM, Bonchek L 1975 Abnormalities of renal perfusion and the renal pressor system in dogs with chronic aortic coarctation. Circ Res 37:615-620

17. Parker FB, Farrell B, Streeten DHP, Blackman MS, Sondheimer HM, Andersen GHJr 1980 Hypertensive mechanism in coarctation of the aorta. Further studies of the renin-angiotensin system. J Thorac Cardiovasc Surg 80:568573 